\title{
An Efficient Protocol for VANET Architecture Design and Performance Improvement
}

\author{
Monica Varmaiya ${ }^{1}$, Sushma Kushwaha ${ }^{2}$, Amit Thakur $^{3}$ \\ M. Tech Scholar, Department of Computer Science Engineering, \\ Swami Vivekanand College of Science \& Tech. Bhopal, India ${ }^{1}$ \\ Assistant Professor, Department of Computer Science Engineering, \\ Swami Vivekanand College of Science \& Tech. Bhopal, India ${ }^{2}$ \\ Associate Professor, Department of Computer Science Engineering, \\ Swami Vivekanand College of Science \& Tech. Bhopal, India ${ }^{3}$
}

\begin{abstract}
Node development highlight of Vehicular Ad Hoc Network (VANET) intently looks like with that of Mobile Ad Hoc Network (MANET) yet its rapid versatility and flighty development qualities are the key contrasting element from that of MANET. The similitude nature proposes that the predominant routing protocol of MANET is especially relevant to VANET. Be that as it may, on a similar line, the difference qualities result in incessant loss of connectivity. This requires up gradation of the current routing protocols to adapt itself into VANET situation. In this paper, proposed On Demand Multicast Routing Protocol (ODMRP). The exhibitions are assessed by fluctuating portability, number of sources and hub speed while parcel conveyance fraction, start to finish deferral and standardized routing load are utilized as execution measurements. The simulations have demonstrated that OMMRP performs nearly superior to DSR and AODV in various versatility models as far as start to finish delay as execution metric.
\end{abstract}

Keywords: VANET, MANET, Protocol, ODMRP

\section{INTRODUCTION}

Node development highlight of Vehicular Ad Hoc Network (VANET) intently looks like with that of Mobile Ad Hoc Network (MANET) yet its rapid portability and unusual development qualities are the key contrasting component from that of MANET. The comparability nature recommends that the predominant routing protocol of MANET is particularly relevant to VANET. Nonetheless, on a similar line, the difference qualities result in regular loss of connectivity. This requires upgradation of the current routing protocols to adapt itself into VANET situation. The key parameter that should be nourished into these protocols is a sensible versatility model which contains criterion connected to speed, road intersections, traffic light impact and so forth. In this paper, we think about exhibitions of responsive routing protocols named Dynamic Source Routing (DSR), Ad hoc On Demand Distance Vector (AODV) and Ad hoc On Demand Multipath Distance Vector (AOMDV) in VANET utilizing diverse Portability Models gave in VANET MobiSim system. The exhibitions are assessed by differing portability, number of sources and hub speed while bundle conveyance fraction, start to finish deferral and standardized routing load are utilized as execution measurements. The simulations have demonstrated that AOMDV performs nearly superior to DSR and AODV in various portability models as far as start to finish delay as execution metric. VANET, which is the remote ad hoc communication between vehicles, has as of late developed as one of the interesting issues in investigations of remote network innovation. Specifically, VANET is utilized in intelligent transportation systems or ITS. The ITS applications have turned out to be increasingly powerful in the momentum driving method of road drivers. One of the unmistakable functions of ITS is to create different sorts of accommodating traffic information to drivers. The drivers can essentially get the encompassing traffic condition, road condition, wellbeing information, business advertisement, and so forth. Besides, VANET can help in rush hour gridlock the executives. Tiaprasert et al. [1] and Comert [2] proposed a procedure to assess the line length by utilizing VANET for traffic light control. In created nations, VANET can gather information. For instance, the Vehicle Information And Communication Framework (VICS) [3] has been propelled in Japan and especially used to convey traffic information to road vehicles. For the rule of VICS, all traffic information from road sensors is sent to a VICS focal server and spread to vehicles on the road framework. As per the VICS, an incorporated information collection plan has an extraordinary advantage on traffic information handling. Nonetheless, there are a couple of disadvantages. To start with, the procedures of both information gathering and scattering between a focal server and road sensors have long deferrals. Second, the achievement of the ongoing applications isn't smooth a result of both absence of the focal server and fast portability of vehicles. Subsequently, information dissemination 
techniques become one of the difficult issues of VANET, which must be investigated for certain upgrades and enhancements.

\section{LITERATURE REVIEW}

In Exploration Paper entitled "Routing Protocols for Mobile and Vehicular Ad Hoc Networks: A Relative Examination" in this paper present near investigation of MANET (Mobile Ad-Hoc Network) and VANET (Vehicular Ad-Hoc Network) routing protocols. The investigation depends on different plan factors. The traditional routing protocols of AODV (Ad hoc On-Demand Distance Vector), DSR (Dynamic Source Routing), and DSDV (DestinationSequenced Distance-Vector) of MANET are using hub driven routing which leads to regular breaking of courses, causing shakiness in routing. [1]

In this paper, creators have introduced information falsification assault detection utilizing hashes for improving network security and upgrading the general execution by adapting contention window estimate while sending exact information to the neighboring vehicles in an opportune way (to improve throughput while decreasing start to finish delay). Creators have additionally displayed bunching way to deal with lessen travel defer time if there should arise an occurrence of traffic congestion.[2]

Execution evaluation is done by utilizing numerical outcomes got from Monte Carlo simulations. Creators saw that the contention window adaptation once information manipulation assault is distinguished outcomes in lower delay and higher throughput than that of fixed contention window estimate. Furthermore, when precise information is transmitted to vehicles, they could settle on educated decision to lessen their holding up time when elective courses are available.[3]

In this paper introduced, execution of AODV and MAODV routing protocol are analyzed as far as the exhibition parameters, for example, parcel conveyance proportion, Normal start to finish delay and routing overhead by utilizing Network Simulator (NS3) for various number of hubs $(25,50,75,100)$ for respite times 2 Secs. [4]

In this paper, an expository model has been exhibited to examine the unwavering quality of the IEEE $802.11 \mathrm{p}$ in VANETs' security and cautioning applications. The investigation depends on another portability model in which the relationship among vehicle thickness, speed, and the pursue on distance guideline is inferred. In the examination, a few components have been considered, for example, the effect of versatility on the connection accessibility between the transmitter and the collector, the distribution of vehicles on the road, and the normal number of vehicles inside the scope of the transmitter. [5]

The proposed model is based on the way that vehicles are broadcasting their status messages inside the SI and model every vehicle as a 1-D Markov chain, including the direct bustling likelihood in each state. The viable greatest communication extend that can be utilized in specific conditions to accomplish a specific effective rate is appeared and by simulation..[6]

This paper introduces a novel multicast routing protocol for mobile ad hoc remote networks. The protocol, named ODMRP (On-Demand Multicast Routing Protocol), is a work based, rather than a conventional tree based, multicast plan and uses a sending bunch concept (only a subset of hubs advances the multicast parcels by means of perused flooding). [7]

Table 1: Comparison between different routing protocols of VANET

\begin{tabular}{|l|l|l|l|l|}
\hline $\begin{array}{l}\text { Protocol } \\
\text { Proposed }\end{array}$ & $\begin{array}{l}\text { Compared with } \\
\text { protocol }\end{array}$ & Comparison parameters & Advantages & Disadvantages \\
\hline VVR & GPSR, AODV & $\begin{array}{l}\text { Delivery ratio, delay, } \\
\text { normalized routing } \\
\text { overhead }\end{array}$ & $\begin{array}{l}\text { Solves the problem of } \\
\text { routing holes problem }\end{array}$ & $\begin{array}{l}\text { Success } \\
\text { delivery through edges is } \\
\text { not guaranteed }\end{array}$ \\
\hline STAR & $\begin{array}{l}\text { GyTAR, GLS, } \\
\text { VVR }\end{array}$ & $\begin{array}{l}\text { Aggregate } \\
\text { throughput }\end{array}$ & $\begin{array}{l}\text { Intersection based } \\
\text { routing protocol used } \\
\text { for urban areas }\end{array}$ & $\begin{array}{l}\text { Less suitable for straight } \\
\text { road }\end{array}$ \\
\hline GLS & GyTAR, STAR & $\begin{array}{l}\text { Average delivery delay, } \\
\text { CDF of delivery ratio }\end{array}$ & $\begin{array}{l}\text { Useful on straight road } \\
\text { communication }\end{array}$ & $\begin{array}{l}\text { Not uneful } \\
\text { intersection of roads }\end{array}$ \\
\hline GyTAR & GSR, LAR & $\begin{array}{l}\text { Delivery ratio vs. } \\
\text { (a)packet sending rate }\end{array}$ & $\begin{array}{l}\text { Limits the control } \\
\text { message overhead, uses }\end{array}$ & $\begin{array}{l}\text { Requires the additional } \\
\text { information of network }\end{array}$ \\
\hline
\end{tabular}


Vol. 8, Issue 6, June 2019

\begin{tabular}{|l|l|l|l|l|}
\hline & & and (b) Nodes number & concept of prediction & \\
\hline GPCR & GyTAR & $\begin{array}{l}\text { Delivery ratio and } \\
\text { throughput }\end{array}$ & $\begin{array}{l}\text { Don't require any } \\
\text { global and external } \\
\text { information i.e. maps }\end{array}$ & $\begin{array}{l}\text { While choosing next } \\
\text { hop, a coordinator node } \\
\text { is preferred rather than } \\
\text { non-coordinator even if } \\
\text { not closet to } \\
\text { no } \\
\text { nestination }\end{array}$ \\
\hline GSR & GyTAR, LAR & $\begin{array}{l}\text { Routing Overhead vs no. } \\
\text { Of nodes }\end{array}$ & $\begin{array}{l}\text { Combines position } \\
\text { based routing with } \\
\text { topological knowledge }\end{array}$ & $\begin{array}{l}\text { Requires additional } \\
\text { information }\end{array}$ \\
\hline VADD & $\begin{array}{l}\text { VADD, H- } \\
\text { VADD, GPSR, } \\
\text { Epidemic }\end{array}$ & $\begin{array}{l}\text { Data sending rate for 150 } \\
\text { nodes and 210 nodes }\end{array}$ & $\begin{array}{l}\text { Support delay tolerate } \\
\text { application in sparsely } \\
\text { connected VANET }\end{array}$ & $\begin{array}{l}\text { Uses predicable vehicle } \\
\text { mobility which limited } \\
\text { to traffic pattern and } \\
\text { road layout }\end{array}$ \\
\hline RSLS & HLS, GLS & $\begin{array}{l}\text { Success rate vs velocity, } \\
\text { success rate vs no. of } \\
\text { vehicles }\end{array}$ & $\begin{array}{l}\text { Is successful in terms of } \\
\text { small and large } \\
\text { scenarios in terms of } \\
\text { success query rate }\end{array}$ & $\begin{array}{l}\text { Not suitable for high } \\
\text { speeds }\end{array}$ \\
\hline RLFF & GPSR & $\begin{array}{l}\text { Packet delivery ratio, } \\
\text { delay and overhead }\end{array}$ & $\begin{array}{l}\text { Suitable for both } \\
\text { intersection and straight } \\
\text { mode }\end{array}$ & $\begin{array}{l}\text { Requires support from } \\
\text { the traffic lights }\end{array}$ \\
\hline
\end{tabular}

\section{RESEARCH GAPS}

A number of localization strategies have been proposed for registering the position of mobile hubs. An intriguing part of vanets is that most localization systems can be connected effectively to these networks. Delineates various localization methods that can be utilized by vehicles to appraise their positions, to be specific Guide Coordinating, Dead Reckoning, Cell Localization, Picture/Video Preparing, Localization Services, Sensors, DSRC, GSM, Radars and Relative Conveyed Ad Hoc Localization.

Routing protocol are principle parts of VANETs. These protocols give an interface and communication between remote gadgets. The examination holes depend on routing protocol. The primary objective for routing protocol is to give ideal ways between network hubs through least overhead. Many routing protocols have been produced for VANETs environment, which can be arranged from multiple points of view, as indicated by various perspectives, for example, protocols attributes, procedures utilized, routing information, nature of services, network structures, routing calculations, etc. Some exploration papers arranged VANETs routing protocols into five classes: topology-based, position-based, geocast-based, broadcast, and group based routing protocols, this classification depends on the routing protocols attributes and strategies utilized. Topology-based routing protocol more often than not a traditional MANET routing protocol, it uses connection's information which put away in the routing table as a premise to advance bundles from source hub to destination, it commonly ordered into three classifications : Proactive (occasional), Responsive (ondemand) and Half and half Therefore the goal of the exploration is:- To actualize the plan and advancements of routing protocols for VANETs

\section{PROPOSED PROTOCOL}

In remote networking, On-Demand Multicast Routing Protocol is a protocol for routing multicast and unicast traffic all through Ad hoc remote work networks. ODMRP makes courses on demand, rather than proactively making courses as OLSR does. This experiences a course acquisition delay, in spite of the fact that it diminishes network traffic when all is said in done. To help decrease the issue of this deferral, a few implementations send the main information parcel along with the course revelation bundle. Since certain connections might be deviated, the way starting with one hub then onto the next isn't really equivalent to the turn around way of these hubs. nodes. 
Vol. 8, Issue 6, June 2019

\section{RESULT}

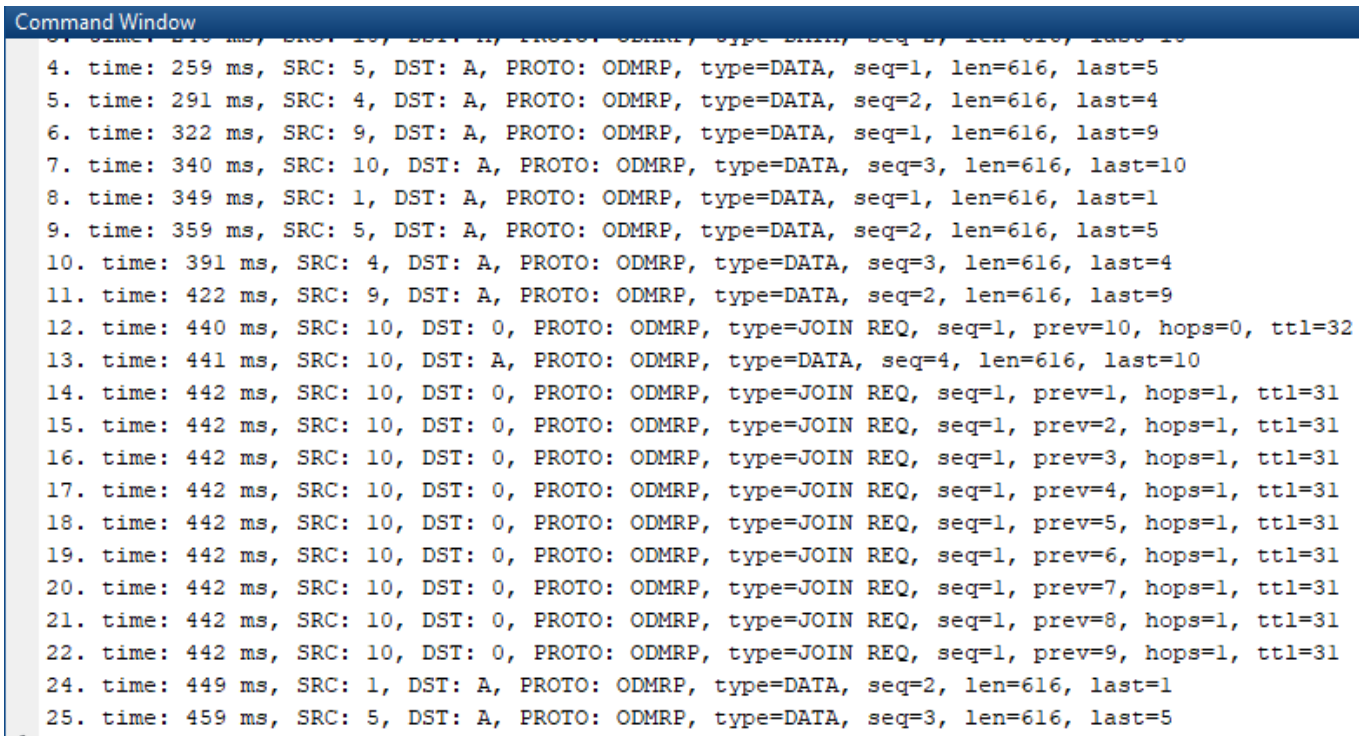

Figure 1: Simulation parameters of proposed protoocol

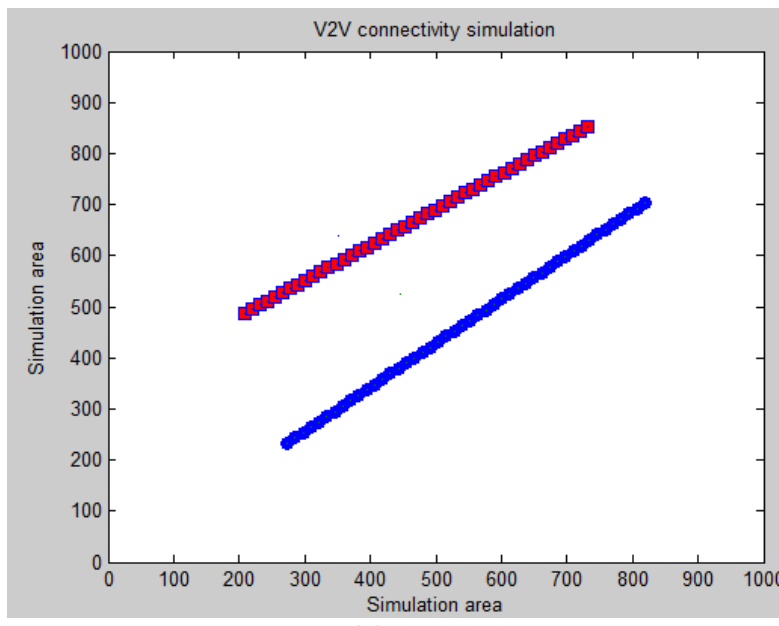

(a)

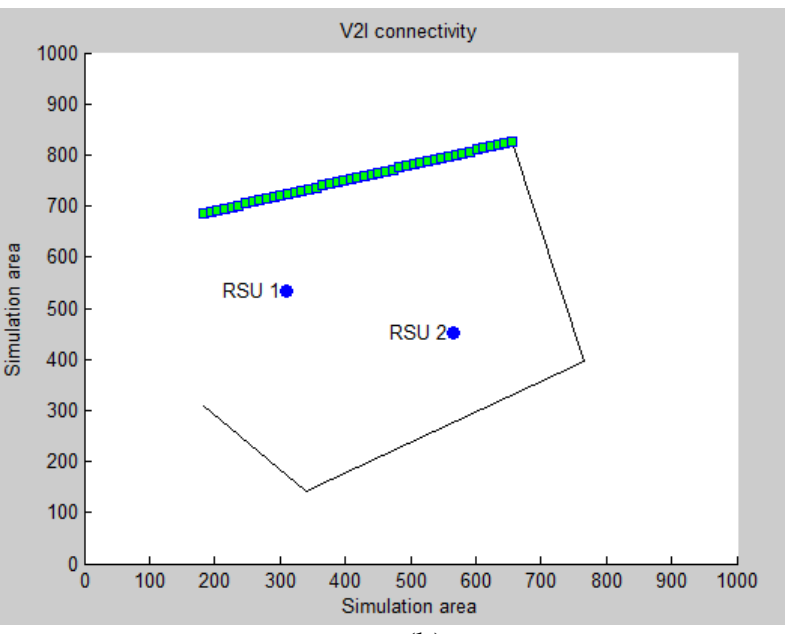

(b)

Figure 2: (a) Simulation of V2V (b) Vehicle-to-roadside communication

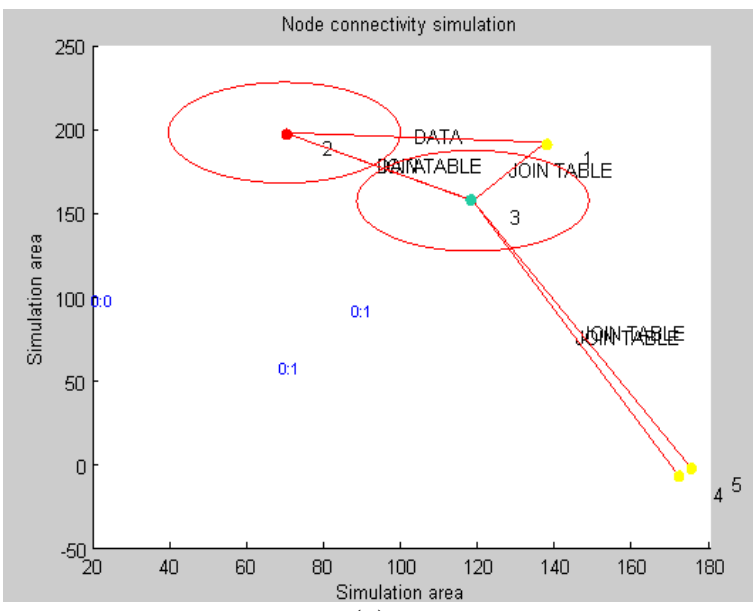

(a)

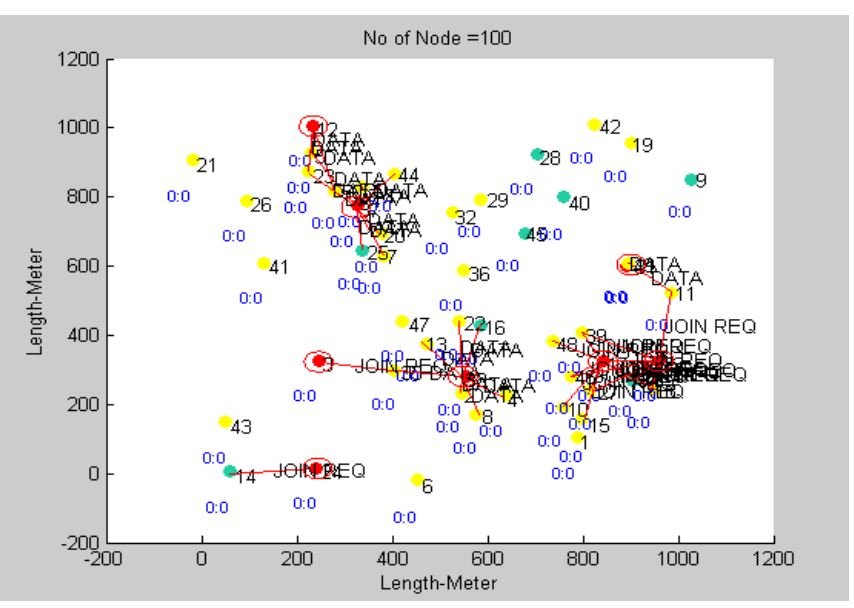

(b)

Figure 3: (a) \& (b) Simulation of VANET using ODMRP 
International Journal of Advanced Research in Computer and Communication Engineering

Vol. 8, Issue 6, June 2019

Table I shows different parameters which included in simulation duration.

Table-1: Simulation parameters

\begin{tabular}{|l|l|}
\hline Software & MATLAB 8.3.0.532 (R2014a) \\
\hline System Environment & Windows 10 \\
\hline Time & $100 \mathrm{~ms}$ to $1000 \mathrm{~ms}$ \\
\hline Destination & $1-100$ \\
\hline Source & $1-100$ \\
\hline Protocol & ODMRP \\
\hline Length & $1200-1200$ \\
\hline
\end{tabular}

Table 2: Performance Parameter (Node $=10)$

\begin{tabular}{|c|c|c|}
\hline Sr No. & Parameter & Value \\
\hline 1 & Protocol & ODMRP \\
\hline 2 & Packet Sent & 27 \\
\hline 3 & Packet Received & 153 \\
\hline 4 & Packets relayed & 18 \\
\hline 5 & Total bytes sent & 6488 \\
\hline 6 & Total bytes received & 43560 \\
\hline 7 & Forwarding efficiency & 1.20 \\
\hline 8 & Aggregated traffic & 3 \\
\hline 9 & Packet delivery ratio & 1 \\
\hline 10 & Single node Time & $801 \mathrm{~ms}$ \\
\hline 11 & Total Simulation Time & $4.51 \mathrm{Sec}$ \\
\hline
\end{tabular}

Table-3 Comparison of Proposed work with previous work

\begin{tabular}{|l|l|l|}
\hline PARAMETER & PREVIOUS WORK & $\begin{array}{l}\text { PROPOSED } \\
\text { WORK }\end{array}$ \\
\hline Routing protocols & AODV, MAODV & ODMRP \\
\hline Number of nodes: & Upto 100 & Upto 100 \\
\hline Simulation Time: & 10.1 secs & 8.39 Secs \\
\hline Simulator: & & MATLAB 2014 \\
\hline Mobility Model: & NS3 & Random way point \\
\hline Area: & Random way point & $1200 \mathrm{~m} * 1200 \mathrm{~m}$ \\
\hline Packet Size & $1000 \mathrm{~m} * 1000 \mathrm{~m}$ & 512 bytes \\
\hline
\end{tabular}

Table 3 shows Comparison of Proposed work with previous work in terms of different parameters like throughput, packet delivery ratio and end to end delay.

Packet Delivery Ratio (Throughput)= Data Rcvd / Data Sent

Control Overhead= Ctrl Bytes Sent / Data Bytes Rcvd

Forwarding Efficiency $=$ Data + Ctrl Packets Sent $/$ Data Packets Rcvd

Total Aggregated Traffic $=$ Data + Ctrl Pkts Tx And Relayed $/$ Ctrl + Data Pkts Rx 
International Journal of Advanced Research in Computer and Communication Engineering

Vol. 8, Issue 6, June 2019

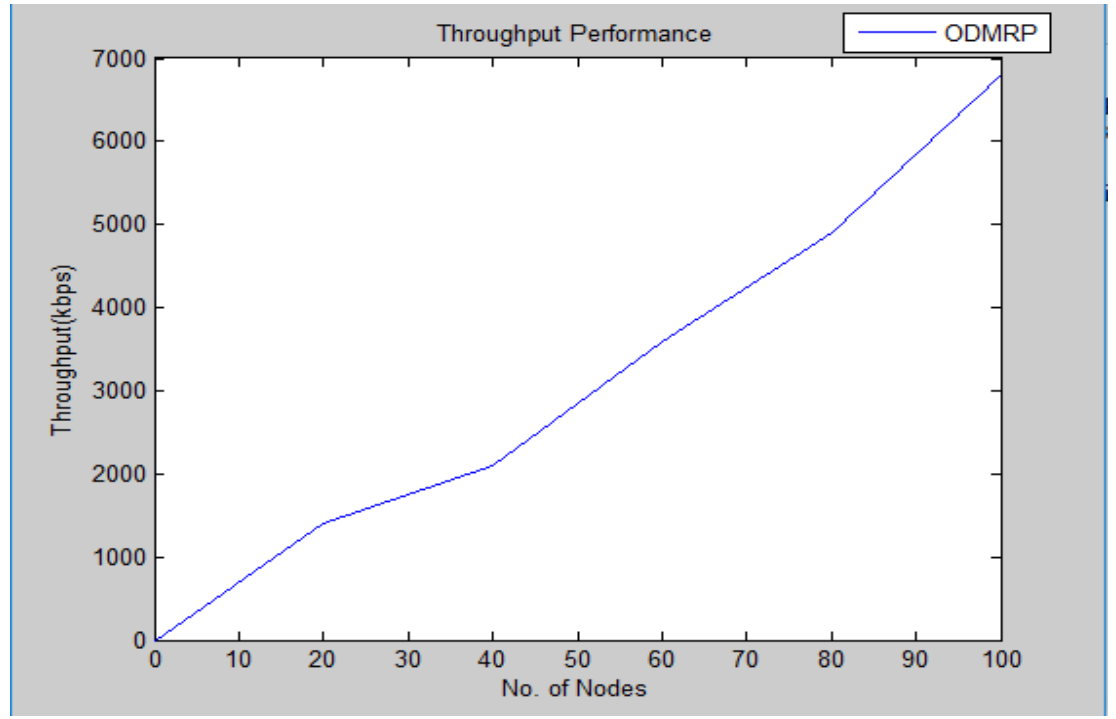

Figure 4: Throughput Performance

Figure 3 shows the performance of data rate or throughput. This is calculated by number of bits transmitted per second in ODMRP Protocol network.

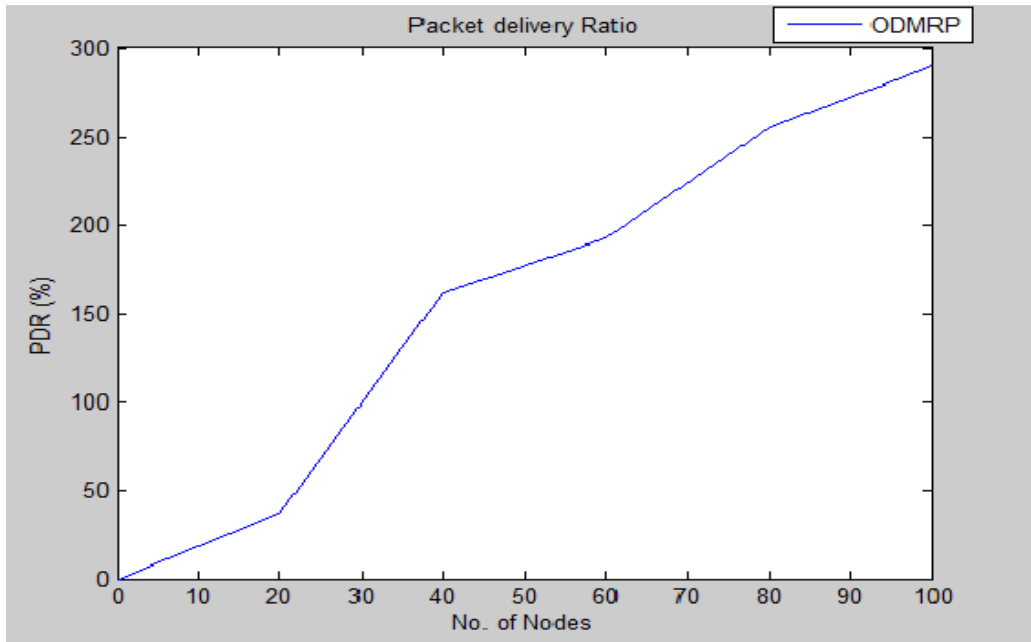

Figure 5: Packet Delivery Ratio

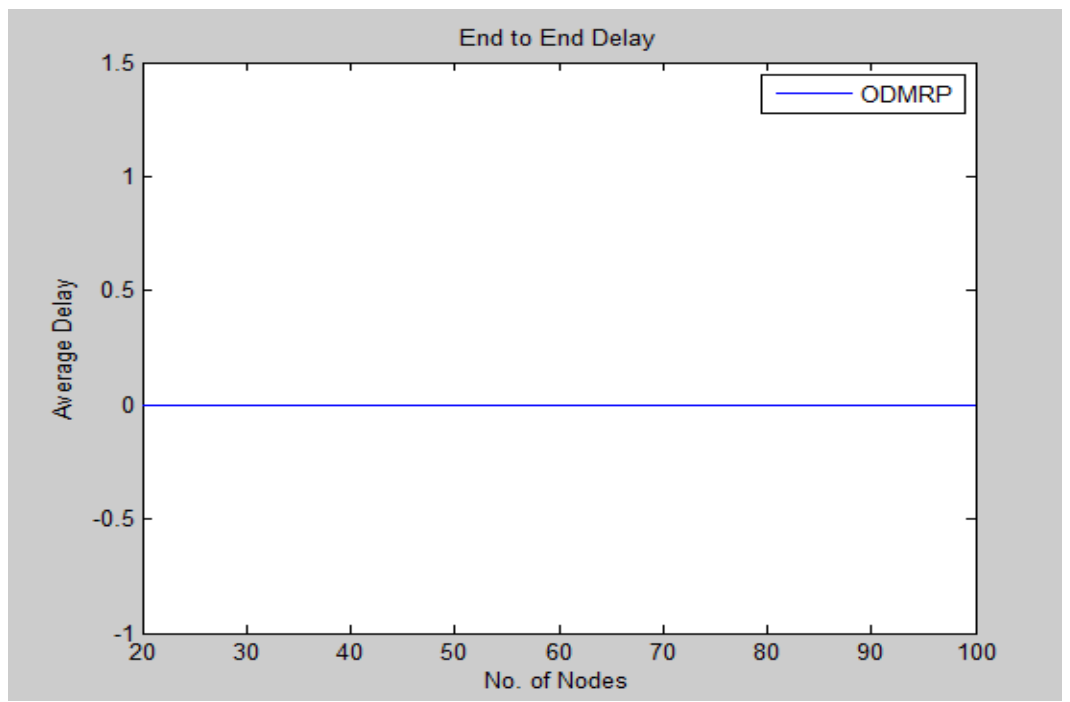

Figure 6: End to End Delay 


\section{CONCLUSION}

An analysis of VANET simulation in a MATLAB has been done and the exhibition parameters have been assessed, for example, start to finish delay, throughput. Execution of ODMRP is contrasted and MAODV and AODV Protocols as far as the exhibition parameters, for example, parcel conveyance proportion, Normal start to finish delay and routing overhead by utilizing MATLAB for various numbers of hubs (upto100). From the outcomes obviously at high portability rate ODMRP performs better if there should arise an occurrence of bundle conveyance proportion, Normal start to finish delay and routing overhead than AODV and MAODV. Henceforth ODMRP give preferable outcome in MATLAB environment over both AODV and MAODV.

\section{REFERENCES}

[1]. Sasirom Tiennoy And Chaiyachet Saivichit "Using a Distributed Roadside Unit for the Data Dissemination Protocol in VANET With the Named Data Architecture" IEEE May 24, 2018,

[2]. Ramon Fontes, Claudia Campolo, Christian Rothenberg.,"From Theory to Experimental Evaluation: Resource Management in Software-Define Vehicular Networks", Digital Object Identifier 10.1109/ACCESS., January 2017.

[3]. S. Tiennoy and C. Saivichit, "Using a Distributed Roadside Unit for the Data Dissemination Protocol in VANET with the Named Data Architecture," in IEEE Access. year 2017

[4]. R. Verma, M. M. S. Rauthan and K. S. Vaisla, "A comparative analysis of multicast routing protocols in VANET for smart city scenario," 2017 International Conference on Inventive Computing and Informatics (ICICI), COIMBATORE, India, 2017, pp. 810-814.

[5]. W. Farooq, M. A. Khan, S. Rehman, N. A. Saqib and M. Abbas, "AAGV: A Cluster Based Multicast Routing Protocol for Autonomous Aerial and Ground Vehicles Communication in VANET," 2017 International Conference on Frontiers of Information Technology (FIT), Islamabad, 2017, pp. 315-320.

[6]. M. A. Khan, W. Farooq, and S. Rehman, "AMVR: A multicast routing protocol for autonomous military vehicles communication in VANET," 2017 14th International Bhurban Conference on Applied Sciences and Technology (IBCAST), Islamabad, 2017, pp. 699-706.

[7]. Z. He, D. Zhang, S. Zhu, J. Cao and X. Liu, "SDN Enabled High Performance Multicast in Vehicular Networks," 2016 IEEE 84th Vehicular Technology Conference (VTC-Fall), Montreal, QC, 2016, pp. 1-5.

[8]. Neelam Sharma et.al "Performance Analysis of Multicast Routing Protocols Using NS-3" IEEE 2016

[9]. I. Rashdan, F. de Ponte Muller and S. Sand, "Performance Evaluation of Traffic Information Dissemination Protocols for Dynamic Route Planning Application in VANETs," 2016 IEEE 84th Vehicular Technology Conference (VTC-Fall), Montreal, QC, 2016, pp. 1-5.

[10]. A. T. Reza, T. A. Kumar and T. Sivakumar, "Position Prediction based Multicast Routing (PPMR) using Kalman Filter over VANET," 2016 IEEE International Conference on Engineering and Technology (ICETECH), Coimbatore, 2016, pp. 198-206.

[11]. W. Farooq, M. A. Khan and S. Rehman, "A cluster based multicast routing protocol for Autonomous Unmanned Military Vehicles (AUMVs) communication in VANET," 2016 International Conference on Computing, Electronic and Electrical Engineering (ICE Cube), Quetta, 2016, pp. $42-48$.

[12]. A. Singh and N. Kaur, "Enhanced Bandwidth Efficient Cluster Based Multicasting Protocol in VANETs," 2015 2nd International Conference on Recent Advances in Engineering \& Computational Sciences (RAECS), Chandigarh, 2015, pp. 1-6.

[13]. Zaydoun Yahya, ET" Communications in Vehicular Networks" Wayne State University, Detroit, Michigan, USA, IEEE 2015.

[14]. I. B. Jemaa, O. Shagdar, F. J. Martinez, P. Garrido and F. Nashashibi, "Extended mobility management and routing protocols for internet-toVANET multicasting," 2015 12th Annual IEEE Consumer Communications and Networking Conference (CCNC), Las Vegas, NV, 2015, pp. 904-909. 